\title{
Biosynthesis and Characterization of Copper Metal Nanoparticles Using Ascorbic Acid
}

\author{
SHRIKAANT KULKARNI \\ Department of Chemical Engineering, \\ Vishwakarma Institute of Technology, Pune (M.S.), India \\ shrikaant.kulkarni@vit.edu
}

Received 1 July 2015 / Accepted 12 July 2015

\begin{abstract}
In this work the particle size control method of copper nanoparticles synthesized using ascorbic acid as a bioreductant and glucose as a biostabilizing agent of sulphate of copper was investigated. The experiments were respectively carried out in a semibatch type reactor. Biosynthesis of metal nanoparticles using green reagents is an important area of research in nanobiotechnology which is an emerging eco-friendly science of well-defined sizes, shapes and controlled monodispersity. The characterization of synthesized NP's was carried out by analytical tools like UV-Vis Spectroscopy, SEM and PSD to ascertain the size and polydispersity of NPs. The UV-Vis absorption spectrum shows its Surface Plasmon Resonance (SPR) leading to a strong band centered at $310 \mathrm{~nm}$ which can be assigned to a ligand-to-metal change transfer (LMCT) transition and other at $453 \mathrm{~nm}$ due to $\mathrm{Cu}$ NP's stabilized by $\mathrm{CuO}$ which is in tandem with the reported data. XRD was also used to unravel the degree of crystallinity and lattice pattern in the biosynthesis of $\mathrm{Cu}$ metal Nanoparticles. It shows that $\mathrm{Cu}$ metal nanoparticles are crystalline but polydispersed and have oblongated face centred cubic (FCC) type of lattice pattern and the average particle size of the order $51 \mathrm{~nm}$. A typical SEM image of the Cu nanoparticles showed the spherical but a bit oblongated morphology of particles with $50 \pm 2 \mathrm{~nm}$ diameter in size. Overall the particles were observed to be polydispersed but uniformly distributed. These results are expected to be of great interest as basic data for the preparation of size-controlled copper nanoparticles by using biosynthetic route.
\end{abstract}

Keywords: Nanoparticles, Vitamin C, Green reagent, UV-Vis Spectroscopy, PSD

\section{Introduction}

Metal nanoparticles (NPs) have important applications in the fields of information storage, catalysis, electronics and optics ${ }^{1,2}$. The most common method employed for the preparation of these NPs is the reduction of metal ions in solution, usually in the presence of a stabilizer. A variety of dispersions can be obtained in terms of their particle characteristics by varying concentrations, redox potential ${ }^{3,4}$, temperature, $\mathrm{pH}^{5,6}$ and surface coatings (polymeric stabilizer). The size and surface charge of nanoparticles govern its interactions with biological systems, including absorption, distribution, metabolism, and excretion ${ }^{7-9}$. 
The species of surfactant used influences the particle size and shape ${ }^{10,11}$. It also affects nanoparticle agglomeration and size distributions in dispersions. Further, in this regard, it is important to know whether these nanoparticles are in an agglomerated (van der Waals interactions between primary particles) or aggregated (chemical bonds between primary particles) state, since their corresponding biological fate and effects will be different ${ }^{12}$.

$\mathrm{Cu}$ along with other metals like $\mathrm{Au}, \mathrm{Ag}, \mathrm{Pd}$ and $\mathrm{Pt}$ and their compounds are widely used these days. Copper as such possesses excellent electrical conductivity. Due to relatively low cost, it contributes significantly to the modern electronic circuits ${ }^{13,14}$ attributed to its characteristic, excellent electrical conductivity, catalytic activity, good compatibility and surface enhanced Raman scattering activity, $\mathrm{Cu}$ nanoparticles have dragged the attention of scientists as a potential candidate in the future nano-devices ${ }^{15}$. In its diverse morphological forms e.g. $\mathrm{Cu}$ nanowires are used in nanoelectronics which have promising applications in the areas like magnetic devices, nanosensors, electron emitters, electronics, nanoprobes in medicines and bio-analytical areas ${ }^{16}$. High temperature superconductivity materials are mostly prepared from $\mathrm{CuO}$ NP's based compounds ${ }^{1}$. $\mathrm{Cu}$ can be used in synthesizing semiconducting antiferromagnetic materials belonging to a class of materials with properties which by virtue of their characteristics find use in diverse areas such as electronic, magnetic, pharmaceutical, cosmetic energy, catalytic and materials applications ${ }^{17,18}$.

A large number of nanoparticles have been prepared most frequently by dispersion of performed polymers ${ }^{19}$ solvent evaporation method and ionic gelation method ${ }^{20}$. In order to produce small particle size, often a high speed homogenization or ultrasonication may be employed. Conventional methods such as solvent extraction-evaporation, solvent diffusion and organic phase separation methods are hazardous to the environment as well as physiological systems. A variety of reducing agents are used to carry out reduction that includes ${ }^{21} \mathrm{NaBH}_{4}, \mathrm{Cu}, \mathrm{Ni}$, Co complexes and macrocyclic ligands. This method avoids the use of hazardous polymers and solvents which are required in excess amounts. The most popular $\mathrm{Cu}(\mathrm{I})^{22}$ and $\mathrm{Cu}(0)^{23}$ nanoparticles emerged as useful and unique green catalysts whose efficiency is attributed to their characteristic high surface to volume ratio that translates into more number of active sites per unit area compared to dominate the properties of matter as size is reduced to nanoscale. As a part of continuing efforts towards the synthesis of $\mathrm{Cu}$ nanoparticles by following a green synthetic methodology by using Ascorbic acid as a bioreductant and glucose as biostabilizing agent is used followed by its characterization ${ }^{24}$.

\section{Experimental}

The chemicals used for experimental purpose were $20 \mathrm{~mL}$ of $\mathrm{CuSO}_{4} \cdot 5 \mathrm{H}_{2} \mathrm{O}(0.001 \mathrm{M}), 60 \mathrm{~mL}$ of Vitamin C (Ascorbic acid, $0.002 \mathrm{M}$ ) as a reducing agent, Glucose, $0.1 \mathrm{~g}$ and all are AR grade Chemicals. Further, water used for preparation of solutions and dilution purpose is Millipore. Solutions have been prepared meticulously by weighing appropriate quantity of chemicals concerned and dissolution and homogenization is brought about by sonication followed by dilution to the requisite strength in accordance with experimental requirement. A known quantity of $\mathrm{CuSO}_{4} .5 \mathrm{H}_{2} \mathrm{O}(0.025 \mathrm{~g})$ as a precursor was added drop wise from burette to known volume of Ascorbic acid $(0.088 \mathrm{~g}$ ) (Chilled with ice for $30 \mathrm{~min}$ ) used as a reductant until a sky-blue colored colloidal solution was obtained in the end with simultaneous measurement of absorbance at regular time interval using UV-Vis spectroscopy in a semibatch process which turned into black after formation of crystalline $\mathrm{Cu}$ nanoparticles. The nanaoparticles so synthesized have been purified by washing with ethanol followed by Milli Q water three times each. Which are further dried and then characterized. 


\section{Results and Discussion}

Figure 1 shows vials containing aqueous solution for colloidal $\mathrm{Cu}$ with its characteristic golden yellow coloured solution. $\mathrm{CuSO}_{4} .5 \mathrm{H}_{2} \mathrm{O}$ using Vitamin $\mathrm{C}$ as a green reducing agent. UV-Visible spectroscopy is an important analytical technique to ascertain the formation and stability of metal nanoparticles in aqueous solution. The rapid colour change of the solution to yellow followed by blue is indicative of the formation of coppers nanoparticles. Further blue colour of the colloidal solution containing $\mathrm{Cu}$ nanoparticles remains intact for a long time which shows the excellent stability of the Cu NP's.

Figure 2 shows the product in the form of $\mathrm{Cu}$ metal nanopowder black in colour.

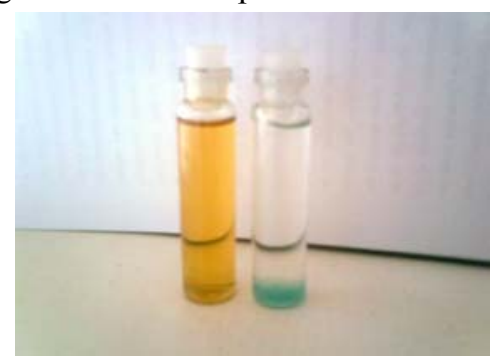

Figure 1. $\mathrm{Cu}$ sols [A] yellowish sol turning to blue sol

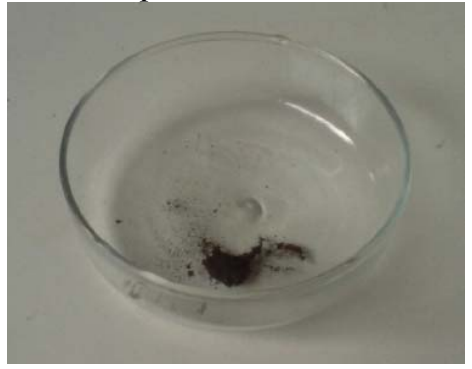

Figure 2. Cu metal nanopowder

Figure 3(a) shows a strong band centered at $310 \mathrm{~nm}$, can be assigned to a ligand-tometal charge transfer (LMCT) transition and Figure (3b) shows a weak band at $453 \mathrm{~nm}$ due to $\mathrm{Cu}$ NP's stabilized by $\mathrm{CuO}$. This is in accordance with the results of other researchers.

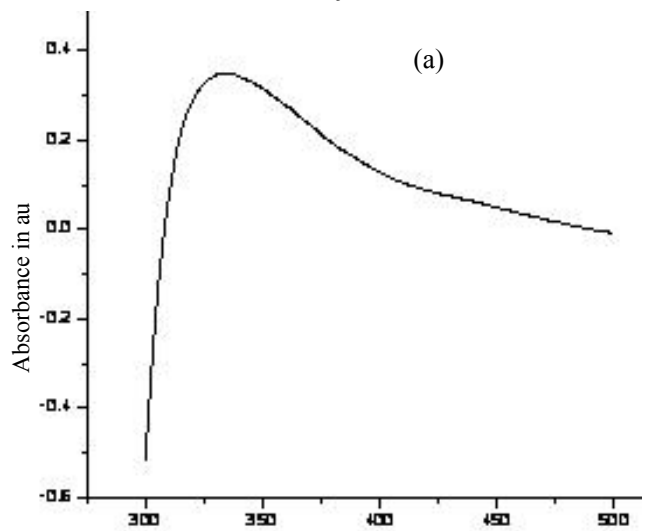

Wavelength, in $\mathrm{nm}$

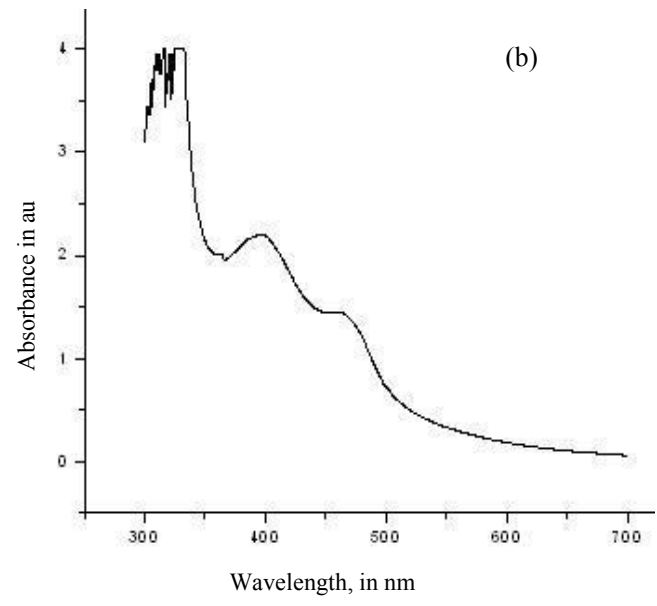

Wavelength, in $\mathrm{nm}$

Figure 3. UV absorption spectrum with SPR at (a) $310 \mathrm{~nm}$ and (b) at $310 \mathrm{~nm}$ and $453 \mathrm{~nm}$

Figure 4 shows that $\mathrm{Cu}$ metal nanoparticles have face centred cubic (FCC.) type of lattice pattern but the particles are polydispersed and possess particle size of the order 45 to $65 \mathrm{~nm}$. The powder XRD shows that crystalline nature with peaks corresponding to $\mathrm{Cu}$ nanoparticles. The metallic nature of $\mathrm{Cu}$ nanoparticles, confirmed by characteristic peak of $\mathrm{Cu}$ nanoparticles was on $2 \theta=31.5$. Crystalline size ' $\mathrm{D}$ ' was obtained by measurement of the broadening of diffraction lines and applying the Debye-Scherer formula 


$$
D=\frac{0.94 \lambda}{\beta \cos \theta}
$$

Where $\lambda$ is the wavelength of XRD radiation, $\beta$ is the full width at half maximum of the peak corresponding to the plane and $\theta$ angle is obtained from $2 \theta$ value corresponding to XRD pattern.

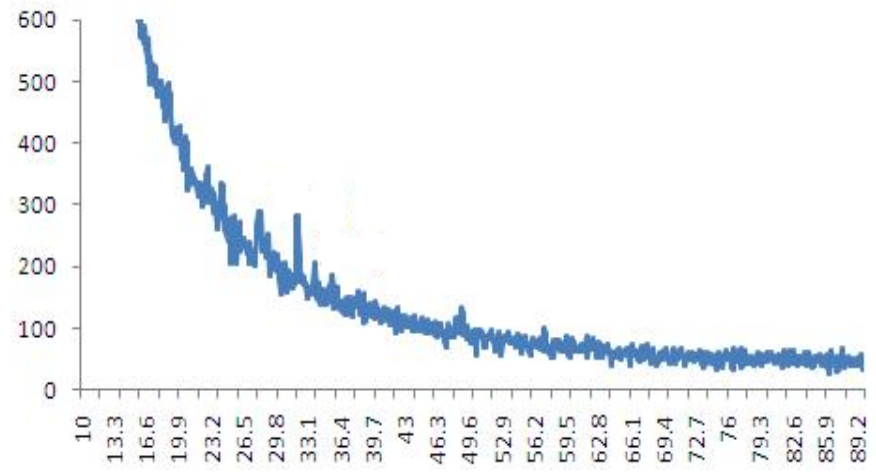

Figure 4. XRD pattern of $\mathrm{Cu}$ nanoparticles stabilized by glucose

The size of the $\mathrm{Cu}$ nanoparticles was confirmed by through scanning electron microscopy (SEM) which shows the spherical particles of $55 \mathrm{~nm}$ diameter. The particles were observed to be polydispersed and uniformly distributed. Although the $\mathrm{Cu}$ nanoparticles appear somewhat non-spherical and oblongated. Thus SEM image confirmed that $\mathrm{Cu}$ metal nanoparticles are in nanorange and they are approximately spherical in shape (Figure 5). The average size of nanoparticles was $53 \pm 2 \mathrm{~nm}$.

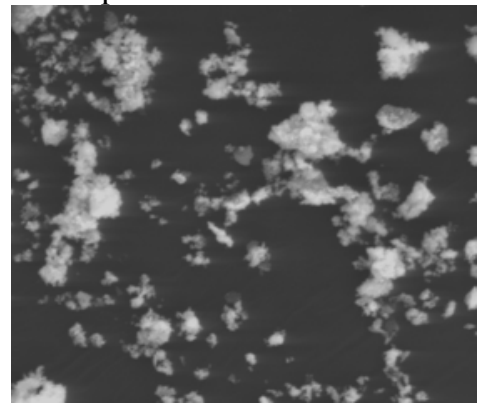

Figure 5. SEM image for $\mathrm{Cu}$ metal nanoparticles

\section{Conclusion}

A facile route to synthesize size controlled $\mathrm{Cu}$ nanoparticles has been developed. Nanoparticles were successfully synthesized by solution reduction method in aqueous media at an ambient condition. The synthesized $\mathrm{Cu}$ nanoparticles were crystalline, highly pure but polydispersed. Glucose which is used as a stabilizing agent controls the particle growth and stabilizes the nanoparticles toward air oxidation. $\mathrm{Cu}(0)$ nanoparticles can be prepared by reduction method which is greener and environmentally suitable, cheap and best as compared to conventional methods. Glucose proved to be an efficient matrix for stabilization of metallic nanoparticles of copper in aqueous medium. This combined with ascorbic acid as reducing agent can be a green approach for the preparation of metallic nanoparticles which can be extended to other noble metals also. 


\section{References}

1. Bhattacharya J, Choudhary U, Biwach O, Sen P and Dasgupta A, Nanomed Nanotechnol Biol Med., 2006, 2(3), 191-199; DOI:10.1016/j.nano.2006.07.001

2. Chandra S and Kumar A, Int J Appl Chem., 2011, 7(1).

3. Chandra S and Kumar A, Int J Appl Biol Pharm Technol., 2011, 2(1), 78-85.

4. Chandra S and Pundir M, Specrochem Acta Part A: Mole Biomole Spectr., 2008, 69(1)A, 1-7; DOI:10.1016/j.saa.2007.02.019

5. Chandra S, Jain D, Sharma A K and Sharma P, Molecules, 2009, 14(1), 174-190; DOI:10.3390/molecules14010174

6. Mitmura $\mathrm{T}$ and Akiya O, Org Lett., 2009, 11(10), 2045-2048; DOI:10.1021/o19001976

7. Pergolese B, Miranda Muniz M and Bigotto A, J Phys Chem B, 2006, 110(18), 92419245; DOI:10.1021/jp0605698

8. Rani S, Suri P, Shishodia P K and Mehra R M, Sol Energy Mater Sol Cells, 2008, 92(12), 1639-1645; DOI:10.1016/j.solmat.2008.07.015

9. Santanu K, Dhrubajoti B and Biswanath M, Chem Phys Lett., 2007, 434(4-6), 265270; DOI:10.1016/j.cplett.2006.12.007

10. Schapter A K, Hu H, Grenier A, Schneider R and Philips F, Appl Phys A Mater Sci Process, 2004, 78(1), 73-75; DOI:10.1007/s00339-003-2199-0

11. Shin-ichi F, Yoshiaki A, Shin-ike T and Nobuaki K, J Org Chem., 2007, 72(21), 8087-8090; DOI:10.1021/jo7013164

12. Tomil Molares M E, Hohberger E M, Schaeflein Ch and Blick R H, Appl Phys Lett., 2003, 82, 13-15.

13. Dragieva I D, Stoynov Z B and Klabunde K, Scripta Mater., 2001, 44(8-9), 2187 2191; DOI:10.1016/S1359-6462(01)00901-0

14. Edelstein A S, Murday J S and Rath B B, Prog Mater Sci., 1997, 42(1-4), 5-21; DOI:10.1016/S0079-6425(97)00005-4

15. Kamyshny A S, Magdassi, Nanoparticles in Confined Structures: Formation and Application, in: Tadros T F (Ed.), Colloid Stability: The Role of Surface Forces. Part I, Wiley-VCH, Weinheim, 2006.

16. Goia D V, J Mater Chem., 2004, 14, 451-458; DOI:10.1039/B311076A

17. Sergeev G B, Russ Chem Rev., 2001, 70, 809-825.

18. Singh M, Sinha I and Mandal R K, Mater Lett., 2009, 63(3-4), 425-427; DOI:10.1016/j.matlet.2008.10.067

19. Renwick L C, Donaldson K and Clouter A, Toxicol Appl Pharmacol., 2001, 172(2), 119-127; DOI:10.1006/taap.2001.9128

20. Borm P J A, Robbins D, Haubold S, Kuhlbusch T, Fissan H, Donaldson K, Schins R, Stone V, Kreyling W, Lademann J, Krutmann J, Warheit D and Oberdorster E, Particle Fibre Toxicol, 2006, 3, 11; DOI:10.1186/1743-8977-3-11

21. Choi H S, Liu W, Misra P, Tanaka E, Zimmer J P, Ipe B I, Bawendi M G and Frangioni J V, Nat Biotechnol., 2007, 25(10), 1165-1170; http://dx.doi.org/10.1038/nbt1340

22. Zhang X, Yin H, Cheng X, Hu H, Yu Q and Wang A, Mater Res Bull., 2006, 41(11), 2041-2048; DOI:10.1016/j.materresbull.2006.04.008

23. Lisiecki I, Billoudet F and Pileni M P, J Phys Chem., 1996, 100(10), 4160-4166; DOI:10.1021/jp9523837

24. Jiang J, Oberdörster G and Biswas P, J Nanopart Res., 2009, 11(1), 77-89; DOI:10.1007/s11051-008-9446-4 